\title{
Uma investigação sobre a luz e seus impactos tecnológicos no cotidiano
}

\author{
Wendell da Silva Cruzeiro' ${ }^{1}$, Marcello Ferreira², Olavo L. S. Filho ${ }^{3}$, Alessandra F. Albernaz ${ }^{4}$ \\ 1, 2, 3, 4 Universidade de Brasília (UnB)
}

Palavras-chave: Bruner; Currículo em Espiral; Ensino de Física; IBSE; Luz; 5E’s.

\section{Introdução}

Os fenômenos eletromagnéticos, provenientes da interação da radiação com a matéria, estão presentes em muitos dispositivos eletrônicos, tais como transistor (presentes em TV's, computadores e celulares), lasers, diodos, displays de cristal líquido e até em aparelhos aplicados à medicina. A compreensão desses fenômenos favorece a aprendizagem significativa da Mecânica Quântica (EISBERG, 1923). As propriedades ópticas, advindas da interação da radiação eletromagnética com a matéria, concernem a aspectos geométricos relacionados ao conceito de raio de luz e à análise das características de alguns elementos específicos, como, por exemplo, espelhos, lâminas de faces paralelas, prismas e lentes. No Ensino Médio, os aspectos concernentes à natureza da luz, sua interação com a matéria e sua ligação com o processo de visão, em geral, são desconsiderados. A motivação deste trabalho consiste em como apresentar, de maneira honesta, tecnologias cotidianas com o intuito de construir conhecimentos relativos à descrição fenomenológica da luz. Portanto, propõe-se a aplicar uma matriz metodológica na construção de sequência didática sobre interações da luz com a matéria através de fenômenos contemporâneos, tais como: espectro eletromagnético, Wi-Fi, Charge Wireless Power Shell (transferência de carga por comando sem fio), Impressoras 3D e Hologramas. Esta pesquisa tem como objetivo proporcionar aos estudantes a aplicação da matriz metodológica que relaciona os tipos de aprendizagem e os 5Es do IBSE, com o intuito de cativar o estudante com a curiosidade e aguçála com finalidade de explicar uma situação. Desta forma, é ativado o processo de educação; ao explicar o conhecimento, ele será iconizado com argumentos e fatos. Estes ícones, juntos, solidificam a aprendizagem com uma simbolização. Serão utilizadas as representações de Bruner sobre a interação da luz e o espectro eletromagnético.

\section{Metodologia}

Metodologicamente, será empreendida a educação científica baseada na investigação (Inquiry Based Science Education - IBSE) ${ }^{1}$, conforme proposto por Costa (2014), que é constituída por cinco etapas dedicadas ao processo de ensino aprendizagem: envolvimento, exploração, explicação, elaboração e avaliação - os denominados $5 E s^{2}$, Bybee (2009). A aderência dessa proposta a situações concretas de ensino na educação básica pode ser amalgamada nas peculiaridades da aprendizagem e categorizada nas proposições sobre ensino de Jerome Bruner, notadamente as apreensões sobre representações ativa (ação), icônica (imaginação) e simbólica (tradução em símbolos). A proposição que se apresenta é a de currículo em espiral de Bruner, no qual um espectador visualiza externamente uma reta progressiva de conhecimento com início em conceitos primitivos e continuum em conhecimentos complexos sobre temas atuais, com variação dos níveis e das formas de abordagem. Bruner (2001) descreve que o mecanismo de aprendizagem se dá pela ativação de uma ação em imagem, que pode ser tornar um ícone dependendo de qual estimulador for a atividade e se consolidar em um símbolo em que traz uma série de significados. O quadro a seguir é a aplicação da matriz metodológica, no qual se podem obter inúmeras combinações correspondentes às características escolhidas. Relacionando à coluna contexto, por exemplo, à investigação, têm-se as seguintes metas: apresentação do fenômeno, experimentar uma situação controlada no qual é semelhante ao problema, relacionar a situação controlada com

\footnotetext{
${ }^{1} \mathrm{~A}$ metodologia do IBSE surge em uma linha construtivista, que tem como necessidade o indivíduo em estágio de aprendizagem e a construção de suas ferramentas de aprendizagem.

${ }^{2}$ Em referência às iniciais dos termos constitutivos da metodologia: Engage (Envolvimento); Explore (Exploração); Explain (Explicação); Elaborate (Ampliação); Evaluate (Avaliação).
} 
o fenômeno, imaginar como resolver o problema e partir para uma situação com maior complexidade.

Quadro 1 - Matriz metodológica: Metas caraterísticas.

\begin{tabular}{|c|c|c|c|c|}
\hline IBSE $\rightarrow$ & Contexto & Autonomia & Gerenciamento & Desenvolvimento \\
\cline { 1 - 2 } Envolvimento & $\begin{array}{c}\text { Enunciar o } \\
\text { Fenômeno }\end{array}$ & Pesquisar & $\begin{array}{c}\text { Debater Conceitos e } \\
\text { leis }\end{array}$ & Articular \\
\hline Exploração & Experimentar & Questionar & Traçar Teorias & $\begin{array}{c}\text { Comparar com a } \\
\text { Ciência }\end{array}$ \\
\hline Explicação & $\begin{array}{c}\text { Examinar uma } \\
\text { Situação Teórica }\end{array}$ & Investigar & $\begin{array}{c}\text { Estabelecer } \\
\text { relevância }\end{array}$ & $\begin{array}{c}\text { Organizar Métodos e } \\
\text { Objetivos }\end{array}$ \\
\hline Elaboração & Imaginar & Construir & Interpretar os dados & $\begin{array}{c}\text { Empregar o } \\
\text { Conhecimento }\end{array}$ \\
\hline Avaliação & Problematizar & Expandir & $\begin{array}{c}\text { Demonstrar em } \\
\text { Linguagem }\end{array}$ & Expressar Habilidade \\
\hline
\end{tabular}

Fonte: Construído pelos autores.

No desenvolvimento da pesquisa, serão desenvolvidas quatro aulas relacionadas à matriz metodológica proposta no ensino de óptica. As aulas serão planejadas para que os alunos desenvolvam a capacidade da observação sistêmica, realizando atividades que compreendam: i) Envolvimento - apresentar o contexto histórico da óptica e pontos que possam ser debatidos, que levante a curiosidade; ii) Experimentação - anotar fatos curiosos sobre a reflexão, refração e absorção; iii) Investigação - utilizar as palavras-chaves na pesquisa em rede; iv) Explicação discorrer sobre o que pesquisou e o que encontrou, como explicar com a pesquisa a decomposição da luz e v) Avaliação - apresentar um problema de caráter mais complexo com o objetivo de consolidar o conhecimento aprendido. Na sequência, os alunos irão elaborar o roteiro de um experimento, com o intuito de instituir as bases para a discussão de problemas de caráter mais complexos.

\section{Conclusões}

É esperado, como resultado dessa pesquisa, a proposição de uma sequência didática que esteja estruturada em aulas centradas no sujeito em aprendizagem e em seus processos de investigação, com ênfase no desenvolvimento de características como: autonomia e capacidade de geração e organização de ideias, de realização de trabalho em grupo e de contextualização com o cotidiano. Por esta aplicação educacional, estima-se uma solidificação do processo de ensino, em que o estudante se torne o protagonista e o professor, o mediador. A aplicação metodológica pode ser uma solução para turmas com problemas de aprendizagem, pois ela busca criar condições para que o aluno se torne um investigador de situações. Nessas investigações, o aluno poderá adquirir habilidades necessárias para resolver problemas de caráter mais complexo, envolver-se com outras áreas do saber e interagir socialmente com os colegas e professores.

\section{Referências}

EISBERG, R. M. Quantum Physics of Atoms, Molecules, Solids, Nuclei, and Particules. New York: Wiley, 1923.

BRUNER, J. S. A cultura da Educação. Porto Alegre: Artmed, 2001.

BYBEE, R. et al. The BSCS 5E instructional model and 21st century skills. USA: National Science Teachers Association, 2009.

COSTA, M. F. M. et al. Pri-Sci-Net: 45 atividades IBSE de aprendizagem das ciências para crianças dos 3 aos 11 anos. Braga: Universidade do Minho, 2014. 